\title{
Defining the Cubature Changes of Historic St. Kinga Chamber in Bochnia Salt Mine, Using Laser Scanning Technology
}

\author{
Anna Szafarczyk ${ }^{1, *}$, and Rafat Gawałkiewicz ${ }^{1}$ \\ ${ }^{1}$ AGH University Science and Technology, Faculty of Mining Surveying and Environmental \\ Engineering, A. Mickiewicza Av. 30, 30-059 Krakow, Poland
}

\begin{abstract}
In Poland, there are many mining enterprises, of historic character registered in the UNESCO World Heritage List. One of the oldest mining enterprises in Poland is the Salt Mine in Bochnia. The processes inside the rock mass require that surveying services carry out regular geometric control of the cavities. A particular attention should be paid (due to its sacral function) on St. Kinga Chamber, located 195 metres below the surface, on the mine level "August". So far measurement technologies have been connected with the studies on changes in the geometry of cavities and based on linear bases used to measure convergence. This only provides discrete information (in a point) and not always presents a real state of deformation. In the scanning method, in practice a three dimension image of changes (structural deformations) is obtained, impossible to determine with the application of measurement methods, applied to measure the value of linear convergence (the method with a limited number of bases). Laser scanning, apart from determining the value of volume convergence, gives also the possibility of the visualization of 3D cavern. Moreover, it provides direct information to update mining numerical maps and make it possible to generate various cross-sections through the cavern. The authors analysed the possibility of the application of laser scanning (scanner Faro Focus 3D), as a modern tool allowing the measuring of the value of volume convergence. Key words - cubature changes, volume convergence, historic mine, laser scanning.
\end{abstract}

\section{Introduction}

Salt is a substance necessary for a human organism to function and develop. The search for salt has been carried out since the pre-historic times. The beginning of salt mining in Bochnia (Poland) goes back to 1248 [1]. Now the Salt Mine in Bochnia is available for tourists, and the tourist route including the one localized on the route going through St. Kinga chapel was in 2013 written into the World Heritage UNESCO List, which makes it necessary to take a particular care about this object.

To make sure that tourists are safe, the mine surveyors periodically make linear measurements of convergence in the St. Kinga Chapel with classical measurement methods meaning periodical measurement of the length of the section between the assembled pairs

\footnotetext{
Corresponding author: szafarcz@agh.edu.pl
} 
of points making measurement bases. These measurements are characterized by high accuracy; however they refer to selected points of the chamber.

In this paper, the possibility of the application of modern measurement technology, which is laser scanning to determine the volume convergence of the chamber. Scanning allows obtaining extensive spatial information on the object being measured, thus some mines in Poland e.g., KGHM-Polska Miedź S.A. apply this technology on daily basis for the inventory of cavities.

\subsection{Geological Structure of the Study Area}

Salt deposit in Bochnia has the shape of a lens extending over the length of $10 \mathrm{~km}$ and width up to $200 \mathrm{~m}$. The depth of the salt bed ranges from 10 to $80 \mathrm{~m}$. It was formed in the form of two main folds (anticlines): the anticline of Bochnia, going directly under the town and smaller anticline of Uzbronia, lying south of the town [1, 2]. A proper salt deposit series (Fig. 1) is built from the layers of anhydrite, siltstone and halite.

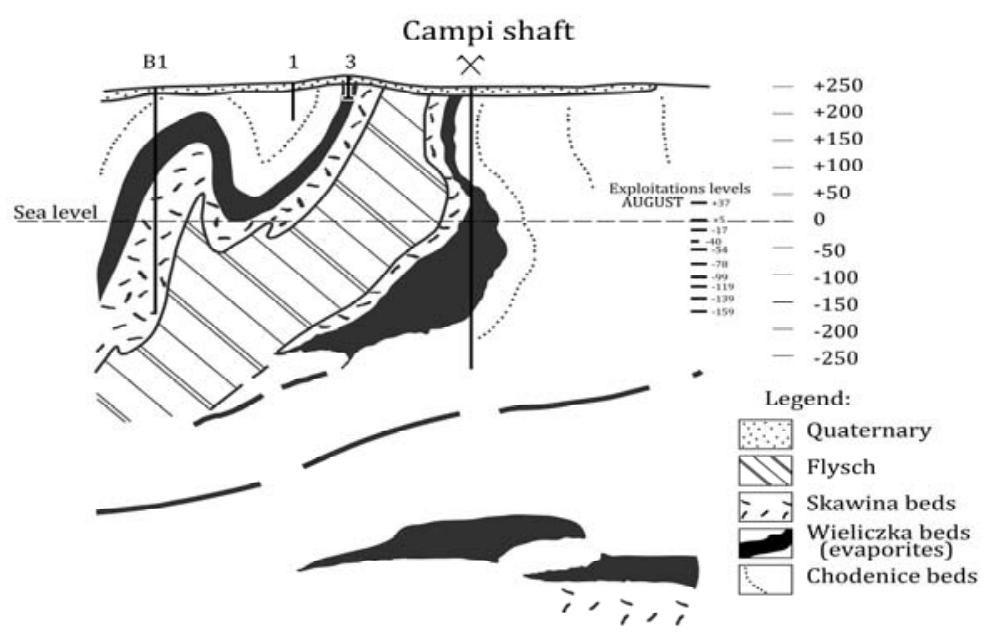

Fig. 1. Cross-section through the rock mass in the neighbourhood of shaft Campi (based on Garlicki A. 1968)

\subsection{The Characteristics of the Objects}

The inventoried chamber excavation is located $195 \mathrm{~m}$ under the surface, on the mine level August, in the distance of about $600 \mathrm{~m}$ west of shaft Sutoris and $400 \mathrm{~m}$ east of shaft Campi, on the way of level August. This was made manually, its shape was semi-elliptic, and the area of the roof support was 5-10 per cent. The chapel was made in the northern halite, consisting of grey fine-grain silt-sand salt, containing some loam and anhydrite. At present, geometric parameters of the chamber excavation, based on the inventory chart and [2] are:

- volume: $800 \mathrm{~m}^{3}$,

- floor area: $312 \mathrm{~m}^{2}$,

- maximal length: $19 \mathrm{~m}$, mean $16.0 \mathrm{~m}$

- maximal width: $15.0 \mathrm{~m}$, mean $12.0 \mathrm{~m}$,

- maximal height: $6.0 \mathrm{~m}$, mean $4.0 \mathrm{~m}$.

The inside of the chamber with the historic altar making the integral part of the excavation was presented in Figure 2. 

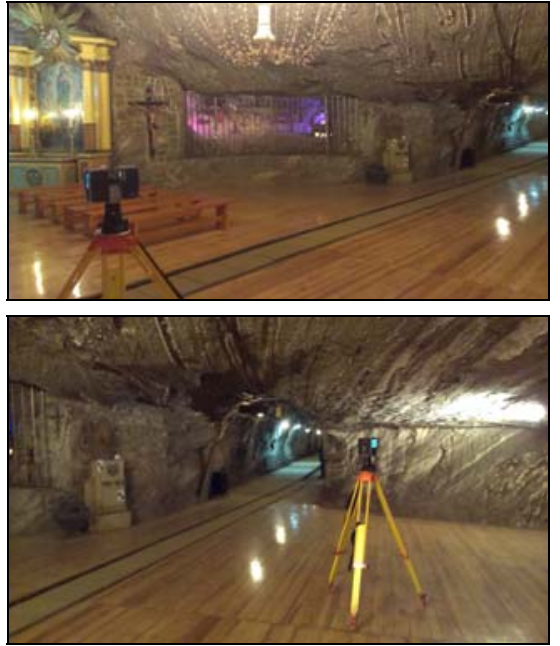

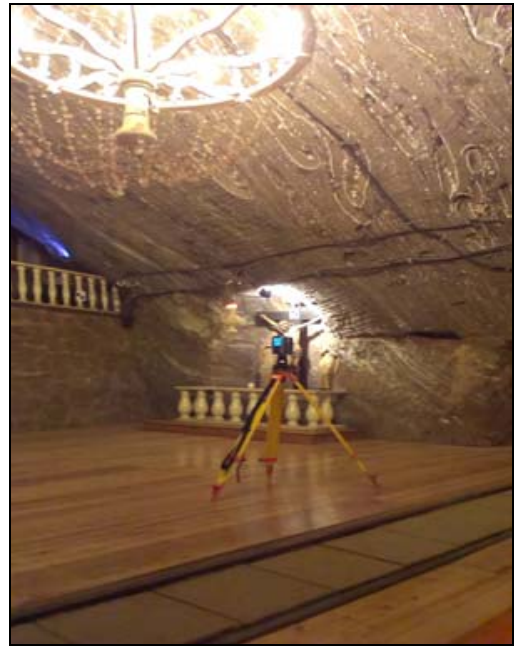

Fig. 2. The inside of St. Kinga Chamber in the Salt Mine Bochnia

\subsection{The Convergence Phenomenon in the Salt Rock Mass}

The phenomenon of the convergence of the cavities of the salt rock mass is usually a long process, which is a result of its specific physical properties. Its characteristic feature includes rheological properties, which are seen in the phenomena of creeping and relaxation. These phenomena show significant influence of time on the behaviour of the rock mass under the influence of load [3]. Laboratory studies on halite showed a linear connection between hydrostatic state of stress and volume strains. In salts permanent strains already occur at smallest changes in strains [4]. Floating of salt is caused by strains and is characterised by the increase of strains in time. The characteristic feature of the halite rock mass convergence is usually the preservation of the continuity of strains and consistence in time. Significant factors influencing the course of the process of the convergence of cavities found in the halite rock mass are temperature and humidity. The growth of the temperature of the rock mass increases the susceptibility of the rock masses on creeping [5]. This process is directly connected with the increase of the depth on which the excavation is located. This relationship can also be observed in periodical measurements of dislocations. In the spring-summer period a greater speed of dislocations was observed than in winter. A significant influence on the value of convergence has also lithological structure of the rock mass, especially if its layers are different in terms of susceptibility to creeping [6]. The presence of the rocks of o low susceptibility to creep in the floor and roof layers for the seam of halite, decreases the value of convergence, both in horizontal and vertical direction.

The paper presents the values of convergence occurring in the St. Kinga chamber in the Bochnia Salt Mine, based on the values of direct linear measurements and the model obtained as a result of the laser scanning of the cavity.

\section{Convergence Measurements in St. Kinga Chapel}

\subsection{Archive Measurements}

Convergence measurements have been made in St. Kinga Chapel since 1993. They are realized two times a year (spring and autumn time). Inside the chapel there is a well developed 
network of the control points (Fig. 3) used mainly to define the convergence value in time. First measurement points of this network were established in 1987.

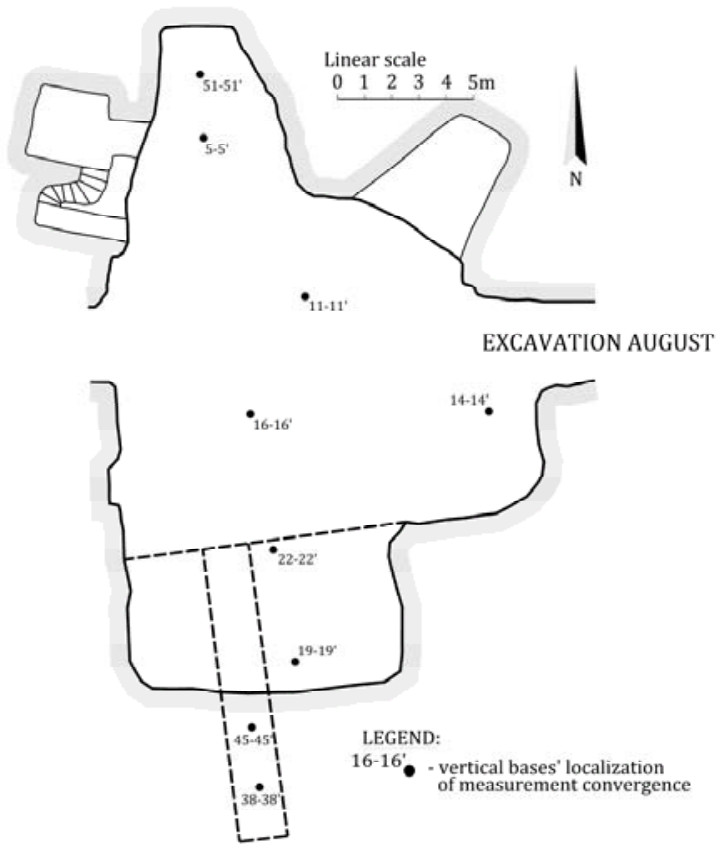

Fig. 3. Distribution of measurement marks in St. Kinga Chapel in horizontal projection (on the basis of materials from the surveying department of the Bochnia Salt Mine)

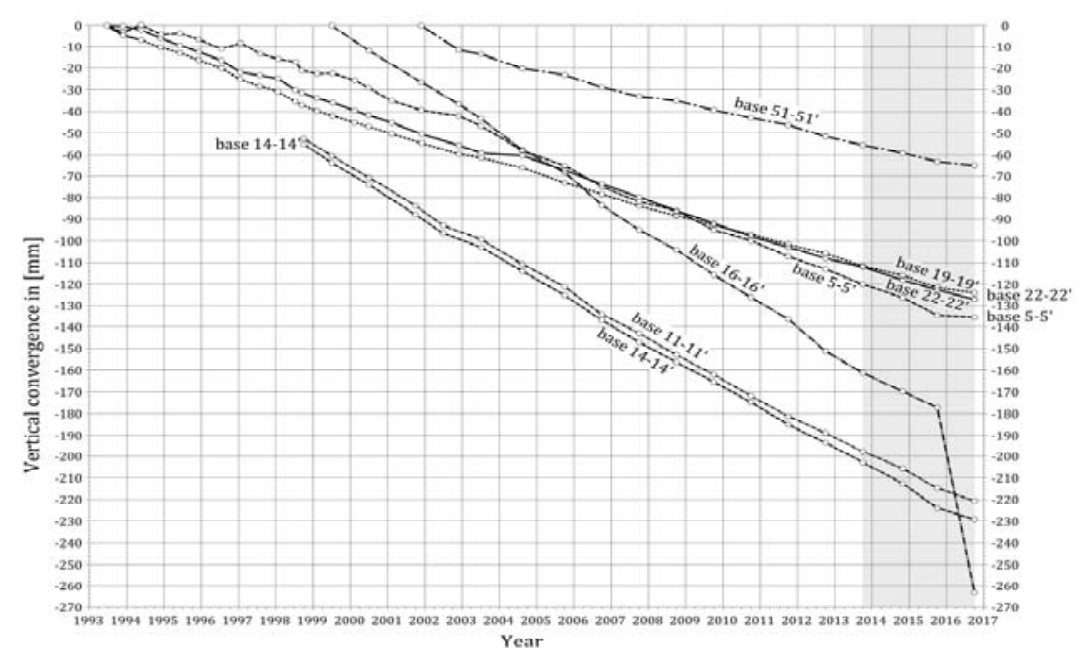

Fig. 4. Vertical convergences in St. Kinga Chapel in 1998-2014

As a result of cyclic measurements the value of the lengths of bases localized inside the chamber are defined. In case of the damage of the base, a new base is established and adjusted to a general measurement concept [4]. The results of the measurements in vertical bases were presented in Figure 4.

In the discussed period of time vertical bases located in St. Kinga Chapel were getting shorter with changeable speed, which was presented in Table 1. 
Table 1. The values of the changes in the lengths of vertical bases in the Chapel of St. Kinga from October 2013 until October 2016

\begin{tabular}{|c|c|}
\hline Base & Changes in the lengths w $[\mathbf{m m}]$ \\
\hline $5-5$ & -15.5 \\
\hline $11-11^{\prime}$ & -22.8 \\
\hline $14-14^{\prime}$ & -26.2 \\
\hline $16-16$ & -102.1 \\
\hline $19-19$ & -12.3 \\
\hline $22-22^{\prime}$ & -14.5 \\
\hline $51-51^{\prime}$ & -9.1 \\
\hline
\end{tabular}

Based on these measurements, the speed of roof subsidence can be defined, which ranges between -0.25 and $-2.8 \mathrm{~mm} /$ month and is relatively uniform in time except base 16-16', where local changes of anomalous convergence have occurred. The greatest values are recorded in the highest central part of the chapel and in its southern and eastern part. In these areas changes on the level $-2.8 \mathrm{~mm} / \mathrm{month}$ were recorded. The smallest changes occur in the northern part of the altar and are about $-0.25 \mathrm{~mm} / \mathrm{month}$. Smaller value of the rate of subsidence is noted for the floor. The subsidence rate is the smallest in the middle of the chamber, and the biggest in the southern zone of the verge of the chapel's floor opposite to the altar. Vertical speed of convergence in the chamber ranges between -0.4 and $1.2 \mathrm{~mm} / \mathrm{month}$ achieves the highest values in the middle of the chamber and diminishes towards the walls of the excavation, which allows favourable assessment of the stability in the whole chamber. The registered horizontal convergence speeds range between -0.3 and $-0.8 \mathrm{~mm} / \mathrm{month}$. Despite relative and absolute movements of the whole region, the outline of the chamber shows great stability [7].

\subsection{Present Measurements}

In the framework of integrated measurements carried out within this study, the technology of laser scanning was applied, due to the fact that, in a short time, allows us to obtain incomparably higher amount of information on the studied object in a numerical version, combined with traditional measurement methods. For the measurement laser scanner FARO FOCUS 3D and reflectorless total station TRIMBLE 5503 DR were applied, and the measurements were carried out in two series in 2013 [8] and in 2016. Every time the co-ordinates of the scanner in the mine system were marked based on the angle-linear measurement, in reference to the same two points of the mine control line; located in the neighbouring gallery cavities. Scans were made in several places and spatially bound based on reference shields used to give geo-reference to the point model. Co-ordinates XYH of the shields in the mine system were marked using the method of spatial indentations, with the application of reflectorless total station Trimble 5503 DR in two series, to increase the accuracy of marking their position.

\subsubsection{Measuring the Subsidence Value of the Chapel's Roof}

Based on the selected points initiated from the cloud, with the kriging method in Surfer program, two roof models were generated. The difference between roof models makes the value of subsidence over the period of three years between the carried out measurements was measured and presented in Figure 5. Data referring to the roof subsidence in the period of 2013-2016, despite relatively short time interval, should be recognized as very accurate (from $2 \mathrm{~mm}$ up to $1 \mathrm{~cm}$ for unfavorable geometric conditions). 
Because of the technology that was applied to obtain them. Generally, the roof of the chamber subsides, and these values uniformly grow in the function of time. In south-eastern part of the chamber there is the area, where uplift was presented (marked yellow) (Fig. 5), however this phenomenon is connected with the occurrence of wooden cribs in this part of the chamber.

\subsubsection{Measuring the Volume Change in the Chapel in 2013-2016}

Using the model of the point cloud in St. Kinga's chamber, generated based on data obtained from laser scanning, made in 2013 and the measurement in 2016, the value of the volume convergence occurring over the 3 years, was measured. To achieve this, the volume of chamber in 2013 and 2016 was calculated in program CloudCompare. The points from both models were given coordinates in local system KS Bochnia (Bochnia Salt Mine), which allowed the isolation from the modes, sets of points covering the same ranges of data. Then, based on selected data, using the option of calculating volume, the values of chamber volume from both measurements were calculated (Table 2).

Table 2. The volume and volume convergence of St. Kinga Chapel

\begin{tabular}{|c|c|c|c|c|}
\hline $\begin{array}{c}\text { Volume in 2013 } \\
{\left[\mathbf{m}^{\mathbf{3}}\right]}\end{array}$ & $\begin{array}{c}\text { Volume in 2016 } \\
{\left[\mathbf{m}^{\mathbf{3}}\right]}\end{array}$ & $\begin{array}{c}\text { Volume } \\
\text { Convergence } \\
{\left[\mathbf{m}^{3}\right]}\end{array}$ & $\begin{array}{c}\text { Volume } \\
\text { Convergence \%o }\end{array}$ & $\begin{array}{c}\text { Volume } \\
\text { Convergence } \\
\text { \%o/year }\end{array}$ \\
\hline 1051.87 & 1044.12 & 7.75 & 7.4 & 2.5 \\
\hline
\end{tabular}

Over the period of 2013 and 2016 the volume of chamber was decreased by $7.75 \mathrm{~m}^{3}$, which corresponds the value of volume convergence equalling $2.5 \%$ o/year, what was done for the first time. Comparison of the used methods (linear convergence and volume convergence obtained using TLS) could not be done in a simply way because of the different character of the obtained data. The accuracy of obtained liner convergence is $2 \mathrm{~mm}$. The accuracy of volume convergence is compilation of several factors such as distance from the object, the angle of laser beam incidence and surface type (roughness and colour) and oscillates between $2 \mathrm{~mm}$ up to $1 \mathrm{~cm}$ for inconvenient geometrical conditions.

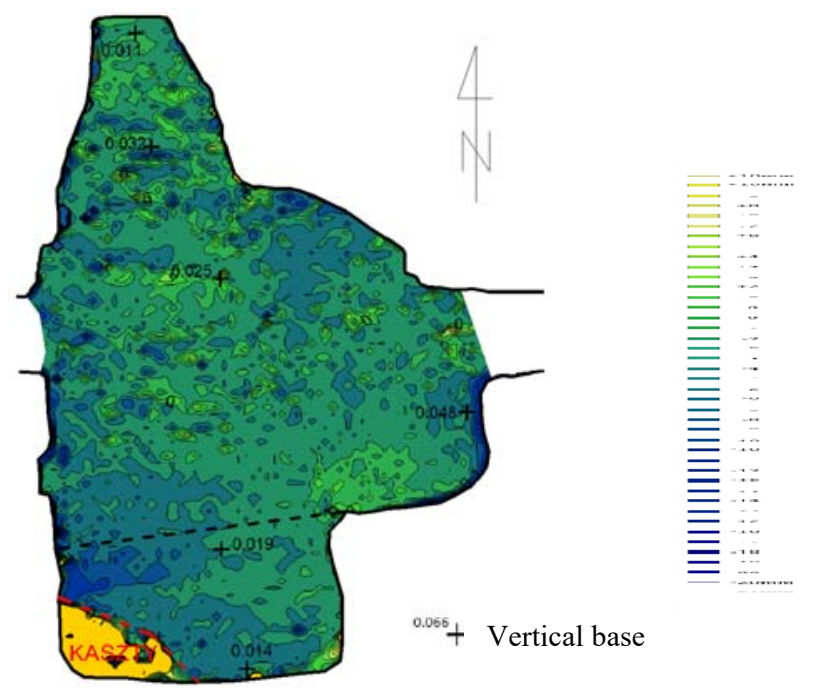

Fig. 5. Subsidence of the roof in St. Kinga Chapel in the period of 2013-2016 (subsidence values given in $[\mathrm{mm}])$ 


\section{Conclusions}

Laser scanning technology is very useful in the inventory and visualization of historic salt chambers $[9,10]$. The implementation of these measurements does not require good light and is carried out automatically. At great resolution of the measured points, scanning technology allows making a quasi-continuous model of the object. Numerical spatial model, obtained as a result of the point clouds obtained from the measurement, gives many extra possibilities in the analyses of the studied object.

The phenomenon of convergence in Salt Mine Bochnia is very small, thus to assess its scale, one has to apply the measurement method guaranteeing high accuracy. The accuracy of measuring the volume of objects with laser scanning, the biggest (fundamental) influence among all the components of situation error in the cloud point is in distance measurement. According to the producer's declaration, assuming distance measurement error as $\pm 2 \mathrm{~mm}$ multiplied by the double floor area $\left(625 \mathrm{~m}^{2}\right)$ and chamber volume measurement error is $\pm 1.25 \mathrm{~m}^{3}$. The difference in volume determined with two measurements is $7.75 \mathrm{~m}^{3}$, which, in case of volume error measurement $\pm 1.25 \mathrm{~m}^{3}$, should be considered significant value from the statistical point of view.

In case of halite excavations, the method of laser scanning fulfils the accuracy requirements connected with the definition of anomaly zones and the change in the geometry of selected cavern elements, e.g., the roof.

Laser scanning is a useful method of observing the phenomenon of convergence, due to the fact of holistic (3D) observations of the character of this phenomenon. One should remember that it has certain disadvantages compared to classical linear convergence measurements. First of all, this technology is significantly more expensive and more time-consuming and complicated. Despite this, it provides incomparably larger amount of information on studied objects, not only in terms of convergence (linear in any direction or volume convergence), but also other parameters, such as e.g., geometry, volume, etc. This is the only method allowing, based on the comparison of two models obtained measurements from different periods of time, defining deformations of any fragment of object, or the whole object in a comprehensive way. Thus, in a direct manner (by contrast to classical method) it allows measuring the value of volume convergence.

In the measurements carried out in one, three-year period, measurable significant results were found, showing the uniform movement of the rock mass in the zone of the localization of the void. The phenomenon of convergence has occurred since the formation of the chamber and will only stop when the excavation is completely converged, thus the use of complex technology (laser scanning) seems to be fully justified in this case.

\section{Acknowledgements}

Article was financed from the grant Badania Statutowe 11.11.150.195.

\section{References}

1. J. Freudenheim, T. Migdas, Restrukturyzacja Kopalni Soli "Bochnia”, Warsztaty z cyklu: Zagrożenia naturalne w górnictwie [Natural threat in mining], Mat. Symp. s. 597-603 (2006)

2. G. Kortas, T. Pałys, R. Dudek, Convergence measurement in the Blessed Kinga Chapel in the Salt mine of Bochnia (1993

3. A. Maj, Opracowanie modelu konwergencji wyrobisk $w$ podziemnych kopalniach soli (2009) 
4. G. Kortas, A. Maj, The assessment of the efficiency of filling the cavities in Salt Mine Bochnia in the context of the protection of the surface and underground historic objects (2013)

5. M. Cardenas, C. LeCompte and G. Cua, Estimation of Permeability of Disturbed Halite Using Inverse Modeling, Groundwater, Vol. 37, Issue 4, pp. 539-545, (1999)

6. G. Wang, K. Guo, M. Christianson, H. Konietzky, Deformation characteristics of rock salt with mudstone interbeds surrounding gas and oil storage cavern, [In:] International Journal of Rock Mechanics and Mining Sciences, Vol. 48, Issue 6, pp. 871-877, (2011)

7. J. Chmura, T. Migdas, The assessment of the stability of the tourist route and sanatory chambers in the salt mine of Bochnia, with the project of the measurement of new tourist objects (2005)

8. J. Maciaszek, D. Madusiok, W. Matwij, The comparison of the results of laser scanning and classical surveying methods of measuring the area and volume in the chapel of St. Kinga in the salt mine of Bochnia (2013)

9. R. Kukutsch, V. Kajzar, P. Konicek, P. Waclawik, J. Ptacek, Possibility of convergence measurement of gates in coal mining using terrestrial $3 D$ laser scanner, In Journal of Sustainable Mining, Vol. 14, Issue 1, pp. 30-37, (2015)

10. T. Lipecki, W. Jaśkowski, W. Gruszczyński, K. Matwij, W. Matwij, P. Ulmaniec Inventory of the geometric condition of inanimate nature reserve Crystal Caves in ,, Wieliczka” Salt Mine, Acta Geodaetica et Geophysica, Vol. 51, Issue 2, pp. 257-272, (2016) 